\title{
Depressive Mood and the Risk of Future Functional Decline in an Elderly Population
}

\author{
Yun Jung Cho', Young Ho Hong ${ }^{2}$, Hyung Jun Park ${ }^{1}$, Ji Eun Lee ${ }^{1}$, Jae Moon Yun ${ }^{1}$, Dong Wook Shin', \\ Ki Young Son ${ }^{1}$, Belong $\mathrm{Cho}^{1}$, Sang Hyuck Kim ${ }^{4}$ \\ ${ }^{1}$ Department of Family Medicine, Seoul National University Hospital, Seoul, ${ }^{2} G$ Clinic, Seoul, ${ }^{3}$ Department of Family Medicine, Seoul \\ Samsung Hospital, Seoul, ${ }^{4}$ Department of Family Medicine, Seoul National University Bundang Hospital, Seongnam, Korea
}

Corresponding Author: Sang Hyuck Kim, MD Department of Family Medicine, Seoul National University Bundang Hospital, 82 Gumi-ro 173beon-gil, Bundang-gu, Seongnam 13620, Korea

Tel: $+82-31-787-7808$ Fax: +82-31-787-4834

E-mail:

fromage5@naver.com

Received: June 16, 2017 Revised: August 16, 2017 Accepted: August 17, 2017

\begin{abstract}
Background: As the elderly population increases in number, prediction and prevention of functional decline in this population are of great importance. This study evaluated whether depression in an elderly population could predict functional decline in activities of daily living and the components of instrumental activities of daily living 2 years after baseline. Methods: Data from the Korean Longitudinal Study of Aging panel, a national, representative sample of aging Koreans, were used. The subjects were the elderly aged 65 years or older who had no disabilities that hindered them from performing activities of daily living at baseline. Depression was measured using the Short-form (10-item) Center for Epidemiological Studies Depression Scale. Multivariable logistic regression analysis was performed to evaluate the effect of functional impairment according to baseline depression. Results: Of the 3,477 participants, $166(4.8 \%)$ showed at least 1 impairment in the 7 activities of daily living (ADL) categories after 2 years. The participants with depression (scored 15 or higher on the depression scale) were more likely to have functional decline 2 years later (odds ratio, 1.82; $95 \%$ confidence interval, 1.23-2.71). All the components of the ADL had an increased tendency to develop functional decline (all odds ratios $>1.00$ ). Furthermore, negative items were significantly associated with functional decline (all $p$-values adjusted for trend<0.05). Conclusion: The participants with depression were more likely to have functional decline 2 years later. Such decline was observed in all types of ADL. Therefore, depression should be monitored and used as a predictor of functional decline in elderly adults.
\end{abstract}

Key Words: Depression, Elderly, Frail elderly, Functional decline, Health status

\section{INTRODUCTION}

The prevalence of depression in the elderly is increasing as the population ages ${ }^{1)}$. Accordingly, late-life depression is associated with an increased medical burden such as hospitalization and the associated costs of medical services ${ }^{2)}$. Furthermore, depression can cause more serious medical issues in the elderly than in younger populations, including cerebrovascular disease, cognitive dysfunction, disability, medical comorbidity, mortality, and social isolation ${ }^{3-5)}$. Therefore, prevention and management of depression in the elderly is of great importance.

Functional decline is defined as limitations in the ability to carry out basic activities of daily living (ADL). In a rapidly aging society, delaying functional decline is key to maintaining the health of community-dwelling elderly ${ }^{6}$. Accordingly, numerous studies have focused on the risk factors associated with functional decline ${ }^{7)}$. By modifying such predictable risk factors earlier, elderly people can maintain better health without functional impairment.

Multiple chronic illnesses and conditions are associated with functional status in the elderly ${ }^{8-10)}$. Furthermore, emotional conditions, including depression, might play an important role in functional decline ${ }^{11)}$. However, most studies focused on the relationship between symptoms of depression and functional decline were cross-sectional and thus could not ascertain causal relationships ${ }^{12-14)}$. Further, to the best of our knowledge, no published studies have evaluated the association between depression and the various ADL and instrumental ADL (IADL). Moreover, as ethnic characteristics could affect depression and related clinical outcomes, ethnicity must be considered when elucidating such relationships regar zding depression ${ }^{15)}$.

The primary aim of the present study was to examine whether depression predicted functional decline in ADL and 
IADL components 2 years after baseline in an elderly population with no initial functional decline. The second purpose was to identify the cultural characteristics of depressive mood in elderly Koreans, using the positive and negative items of the 10-item Center for Epidemiological Studies Depression Scale (CES-D-10).

\section{MATERIALS AND METHODS}

\section{Study Design and Data}

The Korean Longitudinal Study of Aging (KLoSA) is a national longitudinal survey funded by the Ministry of Labor that provides statistical aging-related data based on a representative sample of Koreans aged 45 years or older. It was launched in 2006, with a follow-up occurring in every evennumbered year thereafter. We used the 2012 and 2014 data from the KLoSA. A website freely provides the data to the public. More detailed information regarding data collection and processing is described elsewhere ${ }^{16)}$. This study was approved by the Institutional Review Board of Seoul National University Bundang Hospital (approval number: X-1708-417-903).

\section{Depression Assessment and Inclusion Criteria}

The Center for Epidemiological Studies Depression Scale (CES-D) has been commonly used in clinical settings to measure symptoms of depression in older adults. It is an effective tool for screening for depression in the elderly. The original version of the CES-D contains 20 items. The present study used the briefer 10-item version, which is appropriate for clinical settings ${ }^{17)}$. The short-form CES-D-10 assesses symptoms of depression experienced during the most recent week. The 10 items comprise two items addressing positive affect (i.e., feelings of wellbeing and general satisfaction with life)

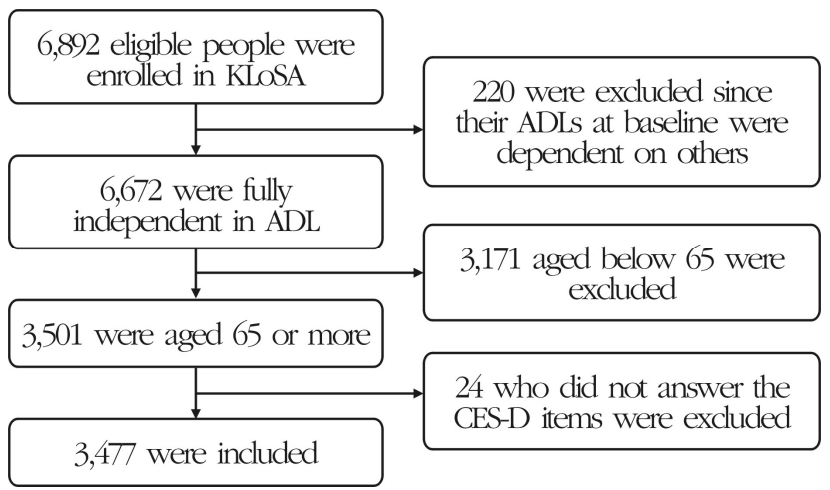

Fig. 1. Flow diagram of inclusion or exclusion of study participants. KLoSA, Korean Longitudinal Study of Aging; ADL, activities of daily living; CES-D-10, 10-item Center for the Epidemiological Studies Depression Scale. and 8 items addressing negative affect (i.e., loss of interest, trouble concentrating, feeling depressed, feeling tired or low in energy, feeling afraid, trouble falling asleep, feeling alone, and hard to get going) ${ }^{16)}$. Responses for each item are made on a scale ranging from 0 to $3(0$, rarely; 1 , occasionally; 2 , often; and 3, almost always for the negative items, with the point values reversed for the positive items). Greater total scores (the sum of the 10 scores) indicate greater symptoms of depression.

Fig. 1 shows the detailed process by which participants were included in the study. A total of 6,892 individuals completed 2 consecutive surveys, of whom 3,415 were excluded for being already dependent on others for ADL $(n=220)$, being $<65$ years of age $(n=3,171)$, or providing no answers to the CES-D-10 $(n=24)$.

\section{Definition of Clinical Variables}

Various optimal cutoff points to define depression using the CES-D-10 score have been suggested ${ }^{18,19)}$. In comparison with the prevalence of major depressive disorder in the Korean elderly (3.3\% to 5.6\%), the current study used a cutoff score of $15^{20)}$ to yield a prevalence rate of $10.3 \%$.

Functional decline was defined as impairment in at least 1 of the 7 domains of ADL (dressing, washing face/hair, bathing, self-feeding, getting out of bed, using the toilet, and maintaining continence ${ }^{10)}$. Additionally, we examined impairment in the 10 items of the Korean version of the IADL scale: (1) grooming, (2) housework, (3) preparing meals, (4) laundry, (5) short trips, (6) using transportation, (7) shopping, (8) managing money, (9) using the telephone, and (10) taking medications.

Considering previous studies of functional decline, possible confounding factors, including medical and socioeconomic status, were selected from the KLoSA survey ${ }^{2,6)}$. Respondents were classified according to their marital status: (1) married or living with a partner or (2) separated or divorced, widowed, or never married.

In Korea, the average monthly income of the wage earners who joined the national health insurance, the occupational pension, and the local pension is 3.29 million Korean Won (KRW) in 2015. The average monthly income of Koreans over 60 years old is 2.5 million $\mathrm{KRW}^{21)}$. Accordingly, the annual income was divided into 2 groups using 30 million KRW as the cutoff value: (1) low income ( $<30$ million KRW) and (2) high income ( $\geq 30$ million $K R W$ ).

The educational levels of respondents were divided into 4 groups: (1) elementary school or less, (2) middle school graduate, (3) high school graduate, and (4) college graduate and beyond. Employment status was assessed by asking the respondents whether they were currently employed. Participants were categorized as living in a major city or the suburbs 
or countryside. Current smoking status and alcohol consumption were assessed. Smoking status was dichotomized as current smoker or ex-smoker or nonsmoker. Regarding alcohol consumption, respondents who drank more than twice a month were distinguished from those who drank less frequently.

Respondents were also categorized as engaging in exercise or not engaging in exercise, depending on whether they exercised at least once a week. Self-reported personal histories of medical conditions, including chronic lung disease, cardiovascular disease, cerebrovascular disease, and malignant neoplasm, were considered as possible cofactors.

\section{Statistical Analysis}

First, we performed univariate analyses of the possible cofactors associated with subsequent functional decline. Factors with $p$-values $<0.1$ in the univariate analyses were included in the subsequent multivariate logistic regression analysis. Multivariate analysis evaluated the association between depression and subsequent impairment in terms of overall ADL impairment and each ADL. We then assessed the association between functional decline and each item of the CES-D-10. Additionally, $p$-values adjusted for trend were calculated to evaluate the association between CESD-10 scores and the number of impaired ADL after 2 years. Further, multivariate logistic regression analysis was performed to evaluate the effect of depression determined according to the CES-D-10 score on subsequent IADL impairment. For the sensitivity analysis, we used a cutoff score of 8 to define depression in order to assess the association between functional decline in ADL and depression ${ }^{22)}$.

All statistical analyses were carried out using STATA ver. 14.0 (Stata Corp., College Station, TX, USA). p-values $<0.05$ were considered statistically significant.

\section{RESULTS}

\section{Baseline Characteristics of the Study Population}

Table 1 shows the baseline characteristics of the study population. Of the 3,477 participants, 166 respondents (4.8\%) showed impairments in at least 1 of the 7 ADL categories. The average ( \pm standard deviation) age of respondents with functional impairment was $78.9 \pm 6.9$ years, whereas the age of those without functional impairment was 73.3 \pm 5.9 years. In univariate analysis, functional decline was associated with married status, low education level, not regularly exercising, and unemployed status. Additionally, participants who lived in urban areas and consumed alcohol socially had a lower risk of functional decline. The prevalence of depression measured by CES-D-10 cutoff scores of 8 and 15 was $48.9 \%$ and
10.3\%, respectively. Depression was significantly associated with subsequent functional decline in univariate analysis $(\mathrm{p}<$ 0.001). The mean CES-D-10 scores in the functional decline and reference groups were $10.4 \pm 6.5$ and $7.7 \pm 5.3$, respectively.

\section{Association Between Functional Decline and Depression}

The results of the multivariate analysis are shown in Table 2. Age, marital status, education level, working status, residence, alcohol drinking habit, regular exercise, chronic lung disease, cardiovascular disease, and cerebrovascular disease were included as confounding factors. Depression assessed by the CES-D-10 predicted 2-year functional decline in the elderly. The participants with a score of 15 or more on the CES-D-10 had greater odds of experiencing functional decline 2 years later (odds ratio [OR], 1.82; 95\% confidence interval [Cl], 1.23-2.71). All the ADL components had increased odds of developing functional decline (all ORs >1.00). When analyzing each $\mathrm{ADL}$ component, the depression group had a notable functional decline in bathing, which was the only statistically significant item (OR, 2.15; 95\% Cl, 1.42-3.26). Moreover, there was a trend toward an increase in the total number of impaired ADL as the CES-D-10 score increased ( $p$ adjusted for trend=0.001) (Fig. 2). In the sensitivity analysis, the CES-D-10 consistently predicted overall functional impairment when using a cutoff score of $8(\mathrm{OR}, 1.44 ; 95 \% \mathrm{Cl}$, 1.02-2.02).

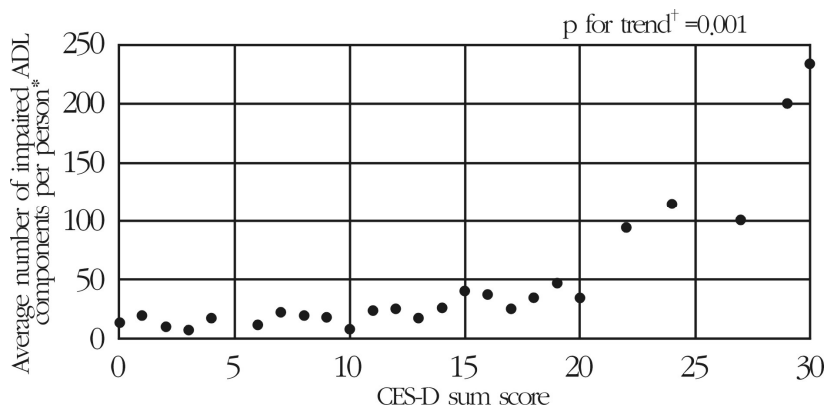

Fig. 2. Association between depression and number of ADL components experiencing decline. "Average number of impaired $\mathrm{ADL}$ components per person calculated as the number of people per each $\mathrm{ADL}$ component category $\times$ the number of ADL components/total number of people within each CES-D-10 sum score category $\times 100$. ${ }^{\dagger} \mathrm{p}$ for trend was calculated to evaluate the association between the number of impaired ADL components and the CES-D-10 summed score (adjusted for age, marital status, educational status, working status, residence, alcohol drinking, and exercise [steady exercise at least once per week], chronic lung disease, cardiovascular disease, and cerebrovascular disease). ADL, activities of daily living; CES-D-10, 10-item Center for the Epidemiological Studies Depression Scale. 
Yun Jung Cho, et al.

Table 1. Comparisons of baseline characteristics of the population with and without functional decline after 2 years

\begin{tabular}{|c|c|c|c|c|}
\hline \multirow{2}{*}{ Characteristic } & \multicolumn{3}{|c|}{ Functional decline } & \multirow{2}{*}{ p-value* } \\
\hline & No $(n=3,311)$ & Yes $(n=166)$ & Total $(n=3,477)$ & \\
\hline Age (yr) & $73.3 \pm 5.9$ & $78.9 \pm 6.9$ & $73.6 \pm 0.1$ & $<0.001$ \\
\hline \multicolumn{5}{|l|}{ Sex } \\
\hline Male & $1,412(42.6)$ & $65(39.2)$ & $1,477(42.5)$ & 0.375 \\
\hline Female & $1,899(57.4)$ & $101(60.8)$ & $2,000(57.5)$ & \\
\hline \multicolumn{5}{|l|}{ Marital status } \\
\hline Married & $2,288(69.1)$ & $92(55.4)$ & $2,380(68.4)$ & $<0.001$ \\
\hline Others $^{\dagger}$ & $1,023(30.9)$ & $74(44.6)$ & $1,097(31.6)$ & \\
\hline \multicolumn{5}{|l|}{ Household income } \\
\hline Low income ${ }^{\dagger}$ & $2,630(79.4)$ & $128(77.1)$ & $2,758(79.3)$ & 0.499 \\
\hline High income & $649(19.6)$ & $36(21.7)$ & $685(19.7)$ & \\
\hline \multicolumn{5}{|l|}{ Educational status } \\
\hline Elementary school & $2,070(62.5)$ & $136(81.9)$ & $2,206(63.4)$ & $<0.001$ \\
\hline Middle school & $460(13.9)$ & $14(8.4)$ & $474(13.6)$ & \\
\hline High school & $543(16.4)$ & $13(7.8)$ & $556(16)$ & \\
\hline College or more & $238(7.2)$ & $3(1.8)$ & $241(6.9)$ & \\
\hline \multicolumn{5}{|l|}{ Employed } \\
\hline Yes & $860(26)$ & $9(5.4)$ & $869(25)$ & $<0.001$ \\
\hline No & $2,451(74)$ & 157 (94.6) & $2,608(75)$ & \\
\hline \multicolumn{5}{|l|}{ Residence } \\
\hline Major city & $1,332(40.2)$ & $55(33.1)$ & 1,387 (39.9) & 0.068 \\
\hline Other & $1,979(59.8)$ & $111(66.9)$ & $2,090(60.1)$ & \\
\hline \multicolumn{5}{|l|}{ Current smoker } \\
\hline Yes & 417 (12.6) & $16(9.6)$ & $433(12.5)$ & 0.260 \\
\hline No & $2,894(87.4)$ & $150(90.4)$ & $3,044(87.5)$ & \\
\hline \multicolumn{5}{|l|}{ Current drinking ${ }^{\mid l}$} \\
\hline Yes & $944(28.5)$ & $21(12.7)$ & $965(27.8)$ & $<0.001$ \\
\hline No & $2,367(71.5)$ & $145(87.3)$ & $2,512(72.2)$ & \\
\hline \multicolumn{5}{|l|}{ Exercise $^{\pi}$} \\
\hline Yes & $1,203(36.3)$ & $36(21.7)$ & $1,239(35.6)$ & $<0.001$ \\
\hline No & $2,108(63.7)$ & $130(78.3)$ & $2,238(64.4)$ & \\
\hline CES-D-10 score (mean, SD) & $7.7 \pm 5.3$ & $10.4 \pm 6.5$ & $7.8 \pm 0.1$ & $<0.001$ \\
\hline \multicolumn{5}{|l|}{ Depression** } \\
\hline Yes & $316(9.5)$ & $41(24.7)$ & $357(10.3)$ & $<0.001$ \\
\hline No & $2,995(90.5)$ & $125(75.3)$ & $3,120(89.7)$ & \\
\hline \multicolumn{5}{|l|}{ Chronic lung disease } \\
\hline Yes & $136(4.1)$ & $14(8.4)$ & $150(4.3)$ & 0.007 \\
\hline No & $3,175(95.9)$ & $152(91.6)$ & $3,327(95.7)$ & \\
\hline \multicolumn{5}{|l|}{ Cardiovascular disease } \\
\hline Yes & $368(11.1)$ & $28(16.9)$ & $396(11.4)$ & 0.023 \\
\hline No & $2,943(88.9)$ & $138(83.1)$ & $3,081(88.6)$ & \\
\hline \multicolumn{5}{|l|}{ Cerebrovascular disease } \\
\hline Yes & $181(5.5)$ & $21(12.7)$ & $202(5.8)$ & $<0.001$ \\
\hline No & $3,130(94.5)$ & $145(87.3)$ & $3,275(94.2)$ & \\
\hline \multicolumn{5}{|l|}{ Malignant neoplasm } \\
\hline Yes & $179(5.4)$ & $13(7.8)$ & $192(5.5)$ & 0.182 \\
\hline No & $3,132(94.6)$ & $153(92.2)$ & $3,285(94.5)$ & \\
\hline
\end{tabular}

Values are presented as mean \pm standard deviation or number (\%).

CES-D-10, 10-item Center for the Epidemiological Studies Depression Scale.

*According to t-test for continuous variables and chi-square test for categorical variables. ${ }^{\dagger}$ Separated, divorced, bereaved, and never married respondents were included. ${ }^{\dagger}$ Earn less than 30 million Korean won annually. ${ }^{\$}$ Local small city and rural areas. ${ }^{\prime \prime}$ Regularly drink at least twice a month. "Engage in steady exercise at least once per week. **Subjects with CES-D-10 summed score $\geq 15$. 
Table 2. Association between depression and subsequent functional decline (total $n=3,477$ )

\begin{tabular}{lccc}
\hline \hline Impaired ADL component (impaired $\mathrm{n}, \%)$ & OR $^{*}$ & $95 \%$ CI & p-value \\
\hline Overall functional decline $(\mathrm{n}=166,4.8 \%)^{\dagger}$ & 1.82 & $1.23-2.71$ & 0.003 \\
Dressing $(\mathrm{n}=89,2.6 \%)$ & 1.47 & $0.85-2.53$ & 0.165 \\
Washing face/brushing teeth $(\mathrm{n}=85,2.4 \%)$ & 1.59 & $0.92-2.75$ & 0.095 \\
Bathing $(\mathrm{n}=138,4.0 \%)$ & 2.15 & $1.42-3.26$ & $<0.001$ \\
Self-feeding $(\mathrm{n}=70,2.0 \%)$ & 1.49 & $0.81-2.74$ & 0.199 \\
Getting out of bed ( $\mathrm{n}=98,2.8 \%)$ & 1.22 & $0.71-2.08$ & 0.476 \\
Using the toilet $(\mathrm{n}=80,2.3 \%)$ & 1.42 & $0.80-2.50$ & 0.232 \\
Maintaining continence in defecation/urination $(\mathrm{n}=75,2.2 \%)$ & 1.63 & $0.92-2.90$ & 0.096 \\
\hline
\end{tabular}

ADL, activities of daily living; OR, odds ratio; CI, confidence interval; CES-D-10, 10-item Center for the Epidemiological Studies Depression Scale.

A CES-D-10 score of $\geq 15$ was defined as depression. Subjects without depression were the reference group.

*ORs were obtained from a logistic regression model, adjusted for age, marital status, educational status, working status, residence, alcohol consumption, exercise (steady exercise at least once per week), chronic lung disease, cardiovascular disease, and cerebrovascular disease. ${ }^{\dagger}$ Impaired $\mathrm{ADL}$ for at least 1 of the 7 components.

Table 3. Association between functional decline and each CES-D item score

\begin{tabular}{|c|c|c|c|c|c|c|c|c|c|}
\hline \multirow[t]{2}{*}{ CES-D 10 component } & \multicolumn{2}{|c|}{$\begin{array}{l}\text { Very rarely or less } \\
\text { than once a day }\end{array}$} & \multicolumn{2}{|c|}{$\begin{array}{c}\text { Some of the time } \\
\text { or } 1-2 \text { days }\end{array}$} & \multicolumn{2}{|c|}{$\begin{array}{c}\text { Much of the time } \\
\text { or 3-4 days }\end{array}$} & \multicolumn{2}{|c|}{$\begin{array}{l}\text { All the time or } \\
5-7 \text { days }\end{array}$} & \multirow{2}{*}{$\begin{array}{l}\mathrm{p} \text { for } \\
\text { trend* }\end{array}$} \\
\hline & OR & $95 \% \mathrm{CI}$ & OR & $95 \% \mathrm{CI}$ & OR & $95 \% \mathrm{CI}$ & OR & $95 \% \mathrm{CI}$ & \\
\hline \multicolumn{10}{|l|}{ Positive questions } \\
\hline I feel pretty good & 0.97 & $0.58-1.60$ & 1.01 & $0.62-1.65$ & 0.62 & $0.36-1.08$ & & Reference & 0.483 \\
\hline I feel generally satisfied & 0.84 & $0.51-1.37$ & 0.83 & $0.51-1.34$ & 0.70 & $0.41-1.18$ & & Reference & 0.757 \\
\hline \multicolumn{10}{|l|}{ Negative questions } \\
\hline I was bothered by things that usually do not bother me & & eference & 0.93 & $0.63-1.37$ & 2.36 & $0.52-3.67$ & 1.80 & $0.79-4.07$ & $<0.001$ \\
\hline I had trouble keeping my mind on what I was doing & & eference & 0.96 & $0.65-1.61$ & 1.33 & $1.10-3.83$ & 1.84 & $0.81-4.19$ & $<0.001$ \\
\hline I felt that everything I did was an effort & & eference & 1.17 & $0.80-1.70$ & 1.45 & $0.91-2.30$ & 1.96 & $0.99-3.87$ & 0.032 \\
\hline I felt depressed & & eference & 1.04 & $0.71-1.51$ & 1.60 & $1.00-2.60$ & 2.58 & $1.24-5.34$ & 0.004 \\
\hline I felt fearful & & eference & 1.29 & $0.89-1.85$ & 1.81 & $1.10-2.97$ & 2.18 & $0.87-5.49$ & 0.003 \\
\hline I had trouble falling asleep & & eference & 1.18 & $0.81-1.72$ & 1.67 & $1.06-2.63$ & 1.83 & $0.89-3.76$ & 0.004 \\
\hline I felt lonely & & eference & 1.22 & $0.85-1.77$ & 1.45 & $0.88-2.38$ & 3.53 & $1.65-7.54$ & 0.003 \\
\hline I could not get "going" & & eference & 1.21 & $0.84-1.74$ & 1.31 & $0.78-2.21$ & 3.11 & $1.45-6.66$ & 0.006 \\
\hline
\end{tabular}

CES-D, 10-item Center for the Epidemiological Studies Depression Scale; OR, odds ratio; CI, confidence interval.

* $\mathrm{p}$ for trend was calculated to evaluate the association between the number of impaired activities of daily living components and CES-D-10 score. ${ }^{\dagger}$ ORs were obtained from a logistic regression model adjusted for age, marital status, educational status, working status, alcohol drinking, residence, exercise (steady exercise at least once per week), chronic lung disease, cardiovascular disease, and cerebrovascular disease.

Table 3 shows the results of the multivariate logistic regression analysis that assessed the association of each CES-D-10 item with functional decline. Consistently, all 8 negative items were significantly associated with functional decline 2 years later (all p-values adjusted for trend were $<0.05$ ). In contrast, the 2 positive items had a tendency to be associated with a lower risk of developing functional impairment, but the associations were not statistically significant ( $p$ adjusted for trend $=0.757$ and 0.483 for "generally satisfied" and "feeling good," respectively). The Cronbach alpha was 0.81 for the 2 positive items and 0.93 for the 8 negative items.

Depression was also significantly associated with subsequent overall IADL impairment (OR, 1.55; 95\% Cl, 1.15-2.08) (Table 4).

\section{DISCUSSION}

The present study revealed that symptoms of depression assessed by using the CES-D-10 could predict future functional decline in elderly Koreans. The large sample size and systematic sampling method support the generalizability of the results. Even after adjusting for the various possible covariates, depression showed consistently significant associations with functional decline in terms of IADL. The results of this study agree with those found in earlier studies ${ }^{9,23)}$. There was a trend toward increasing ORs with the scores of the negative items of the CES-D-10 (all p-values for trend were $<0.05)$. Furthermore, the total number of impaired ADL 
Yun Jung Cho, et al.

Table 4. Subsequent impairment in IADL components according to depression (total $n=3,477$ )

\begin{tabular}{|c|c|c|c|}
\hline \multirow{2}{*}{ Impaired IADL component (impaired n, \%) } & \multicolumn{3}{|c|}{ Depression (CES-D-10 score $\geq 15$ ) } \\
\hline & OR* & $95 \% \mathrm{CI}$ & p-value \\
\hline Overall IADL impairment $(\mathrm{n}=411,11.8 \%)^{\dagger}$ & 1.55 & $1.15-2.08$ & 0.004 \\
\hline Grooming $(n=101,2.9 \%)$ & 1.31 & $0.78-2.23$ & 0.309 \\
\hline Housework $(n=279,8.0 \%)$ & 1.80 & $1.29-2.52$ & 0.001 \\
\hline Preparing meals $(n=356,10.2 \%)$ & 1.68 & $1.22-2.32$ & 0.002 \\
\hline Laundry $(\mathrm{n}=353,10.2 \%)$ & 1.99 & $1.46-2.72$ & $<0.001$ \\
\hline Short trips $(n=279,8.0 \%)$ & 1.49 & $1.06-2.08$ & 0.022 \\
\hline Using transportation $(n=325,9.4 \%)$ & 1.92 & $1.41-2.63$ & $<0.001$ \\
\hline Shopping $(n=232,6.7 \%)$ & 1.65 & $1.15-2.37$ & 0.006 \\
\hline Managing money $(n=246,7.1 \%)$ & 1.23 & $0.85-1.78$ & 0.278 \\
\hline Using telephone $(n=166,4.8 \%)$ & 1.71 & $1.14-2.55$ & 0.009 \\
\hline Taking medications $(n=107,3.1 \%)$ & 1.42 & $0.86-2.35$ & 0.170 \\
\hline
\end{tabular}

IADL, instrumental activities of daily living; OR, odds ratio; CI, confidence interval; CES-D-10, 10-item Center for the Epidemiological Studies Depression Scale.

*ORs were obtained from a logistic regression model, adjusted for age, sex, marital status, educational status, working status, residence, alcohol drinking, and exercise (steady exercise at least once per week), chronic lung disease, cardiovascular disease, and cerebrovascular disease.

${ }^{\dagger}$ Impaired IADL for at least one of the ten components.

components increased with the depression score $(p$ for trend= 0.001). These results and the prospective study design highly support the existence of a causal relationship between depression and functional decline. Cognitive ability is closely related to hippocampus and medial temporal lobe functions. Depression decreases cognitive ability by affecting neuroplasticity. In contrast, antidepressant treatment strengthens neuroplasticity. As such, suitable interventions, such as appropriate medication and exercise, are needed early in the onset of depression ${ }^{24,25)}$. As various cognitive/behavioral therapies are being suggested especially with superiority of group therapy being proved through studies, it also seems necessary to develop and apply new group therapy methods suitable for Koreans ${ }^{26)}$.

When focusing on ADL details, only bathing was significantly associated with depression. This might be because bathing represents functional decline that occurs earlier than other ADL components ${ }^{27)}$. Moreover, as the IADL could be impaired earlier than ADL, 7 IADL items could be significantly associated with depression (i.e., housework, preparing meals, laundry, short trips, using transportation, shopping, and using the telephone $)^{10)}$. Significant relationships may be revealed for other items with a longer follow-up term.

Although many studies have stated that functional decline occurs more[A4] in single than in married persons, our results were contrary to this ${ }^{28)}$. Moreover, according to several studies, the influence of widowhood on functional decline varies with sex, and even late-life older women can be stimulated by widowhood to improve themselves as they emerge from a caregiving role. Therefore, additional study including period of divorce and bereavement is essential ${ }^{29)}$.
When analyzed by CES-D-10 item, the negative affect items showed more consistent relationships with functional decline than the positive affect items. These findings are in contrast to previous research from Japan ${ }^{11}$, which could be related to cultural differences ${ }^{30}$. Koreans tend to experience difficulty in expressing positive emotions, unlike individuals in other countries; this may be a consequence of Confucian ethics ${ }^{31)}$. Therefore, negative emotions can be expressed more easily than positive emotions so that the former are a more precise barometer of elderly functional decline. The aforementioned opposing feelings can have different effects on the prediction of functional decline according to ethnicity and culture ${ }^{31)}$.

Our findings have some important implications. First, older people need to be assessed for depression, and especially for negative feelings that could predict future functional decline in those populations. With early depression treatment, the severity of symptoms and functional impairment could be reduce ${ }^{32}$. Second, in the case of depression in the elderly, modifiable risk factors that cause functional decline (e.g., physical activity, nutrition, hidden disease, and stress factors) should be corrected in their early stages to prevent subsequent functional impairment ${ }^{24,33}$. Finally, additional study is needed to assess whether aggressive treatment for depression has a significant effect on reversing functional decline or preventing future functional decline ${ }^{34)}$.

There were some possible limitations of the present study. First, there might have been other hidden diseases that could have led to poor functionality. However, even after excluding respondents who had newly diagnosed chronic lung disease, cardiovascular disease, or cerebrovascular disease in 2014, 
depression as defined by the CES-D-10 consistently predicted functional decline (data not shown). Second, our research was conducted only for a 2-year period. A longer study would help confirm the detailed effects of depression on ADL/IADL. Third, the data were collected using a self-rated survey, which could be subject to recall bias.

In conclusion, we found that depression was associated with future functional decline in an elderly Korean population. Furthermore, negative affect was more likely to be associated with functional decline than positive affect. It is necessary to identify depression in the elderly population. Further, physicians need to focus on risk-factor modification for preventing functional decline in this population.

Conflicts of Interest Disclosures: The researchers claim no conflicts of interest.

\section{Acknowledgments}

This study was supported partially by the Alumni Fund of the Department of Family Medicine, Seoul National University Hospital.

\section{REFERENCES}

1. Alexopoulos GS. Depression in the elderly. Lancet 2005;365: 1961-70.

2. Alexopoulos GS, Buckwalter K, Olin J, Martinez R, Wainscott C, Krishnan KR. Comorbidity of late life depression: an opportunity for research on mechanisms and treatment. Biol Psychiatry 2002;52:543-58.

3. Mitchell AJ, Subramaniam H. Prognosis of depression in old age compared to middle age: a systematic review of comparative studies. Am J Psychiatry 2005;162:1588-601.

4. Choi NG, Kim J, Marti CN, Chen GJ. Late-life depression and cardiovascular disease burden: examination of reciprocal relationship. Am J Geriatr Psychiatry 2014;22:1522-9.

5. Bush DE, Ziegelstein RC, Tayback M, Richter D, Stevens S, Zahalsky $\mathrm{H}$, et al. Even minimal symptoms of depression increase mortality risk after acute myocardial infarction. Am J Cardiol 2001;88:337-41.

6. Stuck AE, Walthert JM, Nikolaus T, Büla CJ, Hohmann C, Beck JC. Risk factors for functional status decline in communityliving elderly people: a systematic literature review. Soc Sci Med 1999;48:445-69.

7. Sarkisian CA, Liu H, Gutierrez PR, Seeley DG, Cummings SR, Mangione CM. Modifiable risk factors predict functional decline among older women: a prospectively validated clinical prediction tool. The Study of Osteoporotic Fractures Research Group. J Am Geriatr Soc 2000;48:170-8.

8. Colón-Emeric CS, Whitson HE, Pavon J, Hoenig H. Functional decline in older adults. Am Fam Physician 2013;88:388-94.

9. Mehta KM, Yaffe K, Covinsky KE. Cognitive impairment, depressive symptoms, and functional decline in older people. $\mathrm{J}$ Am Geriatr Soc 2002;50:1045-50.
10. Kim SH, Cho B, Won CW, Hong YH, Son KY. Self-reported health status as a predictor of functional decline in a communitydwelling elderly population: Nationwide longitudinal survey in Korea. Geriatr Gerontol Int 2017;17:885-92.

11. Hirosaki M, Ishimoto Y, Kasahara Y, Konno A, Kimura Y, Fukutomi E, et al. Positive affect as a predictor of lower risk of functional decline in community-dwelling elderly in Japan. Geriatr Gerontol Int 2013;13:1051-8.

12. Löwe B, Spitzer RL, Williams JB, Mussell M, Schellberg D, Kroenke K. Depression, anxiety and somatization in primary care: syndrome overlap and functional impairment. Gen Hosp Psychiatry 2008;30:191-9.

13. Ganguli M, Dube S, Johnston JM, Pandav R, Chandra V, Dodge $\mathrm{HH}$. Depressive symptoms, cognitive impairment and functional impairment in a rural elderly population in India: a Hindi version of the geriatric depression scale (GDS-H). Int J Geriatr Psychiatry 1999;14:807-20.

14. Minett TS, Da Silva RV, Ortiz KZ, Bertolucci PH. Subjective memory complaints in an elderly sample: a cross-sectional study. Int J Geriatr Psychiatry 2008;23:49-54.

15. Lidz CW, Parker LS. Issues of ethics and identity in diagnosis of late life depression. Ethics Behav 2003;13:249-62.

16. Jang SN, Cho SI, Chang J, Boo K, Shin HG, Lee H, et al. Employment status and depressive symptoms in Koreans: results from a baseline survey of the Korean Longitudinal Study of Aging. J Gerontol B Psychol Sci Soc Sci 2009;64:677-83.

17. Irwin M, Artin $\mathrm{KH}$, Oxman MN. Screening for depression in the older adult: criterion validity of the 10-item Center for Epidemiological Studies Depression Scale (CES-D). Arch Intern Med 1999;159:1701-4.

18. Björgvinsson T, Kertz SJ, Bigda-Peyton JS, McCoy KL, Aderka IM. Psychometric properties of the CES-D-10 in a psychiatric sample. Assessment 2013;20:429-36.

19. Zhang W, O’Brien N, Forrest JI, Salters KA, Patterson TL, Montaner JS, et al. Validating a shortened depression scale (10 item CES-D) among HIV-positive people in British Columbia, Canada. PLoS One 2012; 7:e40793.

20. Park JH, Kim KW. A review of the epidemiology of depression in Korea. J Korean Med Assoc 2011;54:362-9.

21. Statistics Korea. Employment position statistics in the public sector for 2015 [Internet]. Daejeon: Statistics Korea; [cited 2017 July 28]. Available from: http://kostat.go.kr/portal/korea/kor_nw/ 2/1/index.board?bmode $=$ read $\&$ aSeq $=361207$.

22. Boey KW. Cross-validation of a short form of the CES-D in Chinese elderly. Int J Geriatr Psychiatry 1999;14:608-17.

23. Vaccarino V, Kasl SV, Abramson J, Krumholz HM. Depressive symptoms and risk of functional decline and death in patients with heart failure. J Am Coll Cardiol 2001;38:199-205.

24. Pittenger C, Duman RS. Stress, depression, and neuroplasticity: a convergence of mechanisms. Neuropsychopharmacology 2008; 33:88-109.

25. Drevets WC, Price JL, Furey ML. Brain structural and functional abnormalities in mood disorders: implications for neurocircuitry models of depression. Brain Struct Funct 2008;213:93118.

26. Thompson LW, Coon DW, Gallagher-Thompson D, Sommer BR, Koin D. Comparison of desipramine and cognitive/behavioral therapy in the treatment of elderly outpatients with 
mild-to-moderate depression. Am J Geriatr Psychiatry 2001;9: 225-40.

27. Levy CR, Zargoush M, Williams AE, Williams AR, Giang P, Wojtusiak J, et al. Sequence of functional loss and recovery in nursing homes. Gerontologist 2016;56:52-61.

28. Arber S. Gender, marital status, and ageing: Linking material, health, and social resources. J Aging Stud 2004;18:91-108.

29. Carr D. Gender, preloss marital dependence, and older adults' adjustment to widowhood. J Marriage Fam 2004;66:220-35.

30. Weissman MM, Bland RC, Canino GJ, Faravelli C, Greenwald S, Hwu HG, et al. Cross-national epidemiology of major depression and bipolar disorder. JAMA 1996;276:293-9.

31. Cho MJ, Kim KH. Use of the center for epidemiologic studies depression (CES-D) scale in Korea. J Nerv Ment Dis 1998;186:
304-10.

32. McKnight PE, Kashdan TB. The importance of functional impairment to mental health outcomes: a case for reassessing our goals in depression treatment research. Clin Psychol Rev 2009; 29:243-59.

33. Banerjee S, Shamash K, Macdonald AJ, Mann AH. Randomised controlled trial of effect of intervention by psychogeriatric team on depression in frail elderly people at home. BMJ 1996;313: 1058-61.

34. Ferrucci L, Guralnik JM, Studenski S, Fried LP, Cutler GB Jr, Walston JD, et al. Designing randomized, controlled trials aimed at preventing or delaying functional decline and disability in frail, older persons: a consensus report. J Am Geriatr Soc 2004; 52:625-34. 